\title{
EVALUATION OF A FIRST YEAR DESIGN COURSE
}

\author{
Veltman, T; Rosehart, W. \\ Schulich School of Engineering, University of Calgary, Alberta Canada \\ tiffanyveltman@gmail.com; rosehart@ucalgary.ca
}

\section{INTRODUCTION}

In this paper, we discuss the evaluation of a first year design and communications course, implemented in the Fall of 2010 at the Schulich School of Engineering, University of Calgary.

Operating on the proposition that providing a theoretical framework of design prior to the lab projects would improve the students' ability to follow a design process $^{1}$, the new design and communications course provides lectures on the principles of design, project management, and communication (verbal, written, and graphical), while weekly workshops require the students to apply their theoretical knowledge to practical applications.

The remainder of this paper discusses the evaluation of the effectiveness of this revised course structure, in terms of both the student learning outcomes achieved, and the general student satisfaction of the course. Data was gathered from open and closed-ended surveys, as well as focus groups and interviews. The data from these sources was then triangulated, in order to obtain a holistic impression of the strengths and weaknesses of the course.

\section{EVALUATION METHODS}

We employed surveys and interviews/focus groups, which are two of the most common descriptive study techniques, in order to gather data for the four components of this evaluation ${ }^{2}$.

For the first component, we created a closed-ended survey that was distributed to the students near the conclusion of the course. The survey questions asked the students to report to what extent they agreed with a set of fixed statements that the revised course had developed or enhanced their skills. The skills being evaluated were taken from the CEAB Graduate Attributes criteria ${ }^{3}$ and the CDIO Syllabus ${ }^{4}$, and made reference to the students' skills in the following areas: design, problem analysis, communication(verbal, written, and graphical), project management, teamwork, and consideration of externalities, such as culture, economics, safety, and environment.

The second component of our analysis was a set of open-ended questions at the end of the exit survey, in which we asked the students to identify (among other things) what they learned, and what they perceived the intended learning outcomes of the course to be.

In the third and fourth components of this evaluation, we conducted focus groups with the students, and interviews with the course instructors and teaching assistants (TAs). While there were many elements to these interviews and focus groups, the core focus of these exercises was to determine, and elaborate upon, the course's intended learning outcomes, as perceived by both the students and the instructors/TAs.

The results from the open-ended survey, interviews, and focus groups have been preliminarily analyzed using Grounded Theory, in which the key points of the texts have been extracted and grouped together into concepts 5 .

\section{PRELIMINARY RESULTS}

In order to analyze the data for the first component of this study, we compared the results from the closed-ended survey to the survey responses from the students in the previous implementation of the design course, which had not provided the theoretical background of the course's learning outcomes. This comparison confirmed our initial assumptions that by providing a theoretical foundation to the course's learning outcomes, the students reported a higher self-efficacy in the course's intended learning outcomes, most notably in their ability to understand a design process and apply it to a challenge, evaluate a problem and brainstorm solutions, understand and apply techniques for time management, and work in a team environment ${ }^{6}$.

In the second and third components of this study, we performed Grounded Theory on the open-ended survey responses as well as the focus groups with the students. In large part, the students perceived the learning outcomes of the course to be the same as those predicted by the survey designer, including: understanding and application of the design process, project management skills, working in a team environment, written, verbal, and graphical communication, as well as the purpose of a logbook.
However, the open-ended nature of these components also enabled us to discover that the students perceived additional learning outcomes such as the general purpose of an engineer and their contributions to society, the diversity of engineering, the importance of accepting failure, as well as the challenges, determination, flexibility, patience and professionalism required of an engineer.

In the fourth component of this project, the instructors and teaching assistants were interviewed and asked, among other things, to identify what they perceived the course learning outcomes to be. The instructors and TAs identified that the students should have an understanding of the design process, project management techniques, and communications skills. Many of the instructors then refined and elaborated their responses to link to their area of expertise.

\section{CONCLUSIONS}

From our analysis of the data to-date, we can see that, while the survey design included many potential learning outcomes that both the students and instructors/TAs concurred with, the students identified several additional learning outcomes that they had experienced. By contrast, the instructors and teaching assistants largely stuck to the basic course learning outcomes that were stated in the course outline. This provides an interesting perspective to the evaluation of the first-year design course. By employing qualitative metrics, we enabled students to provide insights into additional learning outcomes, while also enabling the instructors to focus on the core learning outcomes of the course and refine them.

\section{REFERENCES}

1. Atman CJ, Bursic KM, Teaching Engineering Design: Can Reading a Textbook Make a Difference?, Research in Engineering Design, 1996, pp. 240-250.

2. B. Olds, B. Moskal, and R. Miller, "Assessment in Engineering Education: Evolution, Approaches, and Future Collaborations", Journal of Engineering Education, 94,1, Jan 2005, pp. 13-25.

3. Accreditation Criteria and Procedures 2008, Canadian Engineering Accreditation Board, 2008, http://www.engineerscanada.ca/e/files/ report_ceab_08.pdf

4. CDIO Syllabus, CDIO, http://www.cdio.org/framework-benefits/cdiosyllabus

5. Glaser B, Strauss AL, The discovery of grounded theory: Strategies for qualitative research, 1967.

6. Veltman T, Rosehart W, Eggermont M, Onen D, Evaluation and Analysis of Freshman Design Courses in Engineering, Procedings from the $118^{\text {th }}$ Annual Conference for the American Society of Engineering Education, June 26-29 2011. 